showed positive effects on sick leave, two studies showed effects on work performance, one study showed effects on work ability and one study showed effects on productivity.

Discussion The scientific evidence shows that it is possible to influence work-related outcomes, especially sickness absence, positively through health promotion efforts that include components aimed at the workplace's physical work environment and organisational structure. There is a lack of knowledge regarding the impact of interventions on work ability, work performance and productivity and thus more research is needed. In order to draw further conclusions regarding workrelated outcomes in controlled high-quality studies, long-term follow-up using objective outcomes and/or quality assured questionnaires are required.

\section{ATTITUDES TO THE ROLE OF GOVERNMENT, PERCEIVED WORK-RELATEDNESS AND THE COMPENSABILITY OF MESOTHELIOMA: A SURVEY OF MEDICAL AND LEGAL PROFESSIONALS}

${ }^{1}$ Fan-Ju Hsiao* ${ }^{1}$ Yawen Cheng, ${ }^{1,2}$ Chieh-Jan Chen ${ }^{1}$ Institute of Health Poligy and Health Management, College of Public Health, National Taiwan University; ${ }^{2}$ National Institute of Environmental Health Sciences, National Health Research Institutes, Taipei, Taiwan

\subsection{6/oemed-2018-ICOHabstracts. 1117}

Introduction Despite of the strong link between occupational asbestos exposure and mesothelioma (MM), only a small fraction of $\mathrm{MM}$ are recognised and compensated as occupational disease (OD). Lack of awareness of health risks of asbestos and negligence of workers' compensation rights may be underlying factors for low recognition of occupational diseases. While medical and legal professionals are key players in the compensation process, their knowledge and attitudes towards disease causation and compensability of $\mathrm{MM}$ as well as attitudes towards welfare state policies are not well understood.

Methods An anonymous survey was conducted among 281 physicians and 929 legal professionals in Taiwan. Provided in the questionnaire was a vignette case. Study participants were asked to comment on the work-relatedness and compensability of the case. Also included was an 8-item scale of the role of government adopted from the International Social Survey Programs to assess participants' attitudes towards welfare state policies.

Results $10.7 \%$ of physicians and $2.7 \%$ of legal professionals considered the case as an OD with certainty. Uncertainty was much higher in legal professional, as $53.1 \%$ of them could not give an answer on this issue. Despite of uncertainty, the majority of physicians (85.1\%) and legal professionals $(56.6 \%)$ agreed that such a case should be compensated under the workers' compensation scheme. After excluding participants who could not answer the question on the work-relatedness of disease, we found that those with lower scores in the role of the government scale were more likely to disapprove $\mathrm{MM}$ as an OD and to disagree its compensability.

Conclusion Findings of this study suggest that attitudes of medical and legal professionals towards the compensability of asbestos-related mesothelioma are influenced not just by their knowledge about asbestos hazards and epidemiologic features but also by the ideas they hold about the role of the government in social protection.

\section{OCCUPATIONAL EXPOSURE TO COMBUSTION PRODUCTS AND RISK OF DEVELOPING RHEUMATOID ARTHRITIS}

${ }^{1}$ Anna llar* ${ }^{1,2}$ Pernilla Wiebert, ${ }^{3}$ Saedis Saevarsdottir, ${ }^{3,4}$ Johan Askling,, 1,2Per Gustavsson, 1,2Lars Alfredsson. 'The Institute of Environmental Medicine, Karolinska Institutet, Stockholm, Sweden; ${ }^{2}$ Centre for Occupational and Environmental Medicine, Stockholm County Council, Stockholm, Sweden; ${ }^{3}$ Rheumatology Unit, Department of Medicine, Karolinska University Hospital and Karolinska Institutet, Stockholm, Sweden; ${ }^{4}$ Unit of Clinical Epidemiology, Department of Medicine, Karolinska University Hospital and Karolinska Institutet, Stockholm, Sweden

\subsection{6/oemed-2018-ICOHabstracts.1118}

Introduction Studies have suggested a potential association between traffic pollutants and rheumatoid arthritis (RA), but findings have been inconclusive. We therefore assessed the risk of RA from occupational exposure to combustion products in a large population-based case-control study.

Methods We included participants living in Sweden from 2006 to 2013. Incident cases of RA were enrolled from the Swedish Rheumatology Quality Register. Ten controls per case, matched on sex, age and county, were enrolled from the total population register. Work histories were available through population and housing censuses. We estimated exposure to asphalt fumes, diesel engine exhaust (DEE) and polycyclic aromatic hydrocarbons (PAH) from 1955 to 1995 with job-exposure matrices. Conditional logistic regression was used to estimate the risks of two histological subtypes of RA (seropositive or seronegative RA) from exposure to either of the combustion products taken separately or all of them combined. All estimates were adjusted for potential confounding from respirable crystalline silica dust and household disposable income.

Results We analysed 9180 cases and 81367 controls. Ever exposure to DEE in men was associated with a marginally higher risk of seropositive RA (OR: 1.11, 95\% CI: 1.00 to 1.23), which was slightly higher among workers with at least 20 years of exposure (OR: 1.22, 95\% CI: 1.00 to 1.49). More than 20 years of asphalt fumes exposure was also associated with a higher risk estimate for seropositive RA among men (OR: 1.87, 95\% CI: 1.05 to 3.31). Being exposed to asphalt fumes, DEE or PAH combined for more than 20 years resulted in an OR of 1.22 (95\% CI: 1.03 to 1.45 ) among men and 1.27 (95\% CI: 0.50 to 3.26) among women for seropositive RA.

Discussion Long-term exposure to combustion products may increase the risk of seropositive RA among men after adjustments for respirable crystalline silica dust and household disposable income.

\section{A POSITION PAPER ON THE FUTURE REQUIREMENTS FOR OCCUPATIONAL HEALTH PHYSICIANS IN THE PUBLIC HEALTH SERVICE, IRELAND}

L Sisson*, S Carolan. Workplace Health and Wellbeing Unit, HSE, Human Resources, Dublin, Ireland

\subsection{6/oemed-2018-ICOHabstracts.1119}

Introduction At a time when health resourcing costs are contracting, it is vital that services examine the potential to maximise the efficiency of their services and resources. The 